Claves. Revista de Historia, Vol. $5, \mathrm{~N}^{\circ} 8$

Montevideo, enero - junio 2019

(pp. 153 - 179) ISSN 2393-6584

DOI: http://dx.doi.org/10.25032/crh.v5i8.7

\title{
Roles y representaciones de la mujer obrera según la publicación sindical iLucha! de la industria de la carne (Uruguay), 1946-1952
}

\author{
Roles and portrayals of working women according to the \\ meat industry trade union publication Lucha! (Fight), \\ 1946-1952.
}

\author{
Alesandra Martínez Vázquez \\ Universidad de la República
}

Recibido: 29/04/2019

Aceptado: 22/05/2019

Resumen: El presente artículo aborda desde una perspectiva de género, los roles que deberían desarrollar las mujeres obreras según periódicos sindicales de la industria de la carne publicados en el Cerro de Montevideo en el período 19461952. En base a artículos del periódico iLucha! de la Federación Autónoma de la Carne, se observarán las representaciones sobre el trabajo, la maternidad, las consideraciones sobre el respeto y los preceptos morales que se expresan sobre las mujeres. También, se atenderá a las dificultades y planteos que se presentan con el fin de incorporar a las mujeres en el ámbito sindical. Se intenta rescatar la participación de las mujeres, además de prestar atención y desentrañar nociones de género en el pensamiento y en las prácticas de la clase trabajadora en una época determinada.

Palabras clave: Mujeres - roles de género - prensa sindical - frigoríficos cultura trabajadora

\footnotetext{
Abstract: The present article approaches from a gender perspective, the roles that women workers should develop according to trade union newspapers of the meat industry published in the Cerro de Montevideo in the period 1946-1952. Based on newspaper articles iLucha! of the Federación Autónoma de la Carne,
} 
the representations on the work, the motherhood, the considerations on the respect and the moral precepts that are expressed on the women will be observed. Also, the difficulties and proposals presented in order to incorporate women in the trade union sphere will be addressed. It attempts to rescue the participation of women, in addition to paying attention and unraveling notions of gender in the thinking and practices of the working class at a given time.

Keywords: women - gender roles - trade union press - meat industry meatpacking- working culture

\section{Introducción}

El Uruguay, al igual que en otros países de la región, fue elegido para el emplazamiento de la industria de la carne. El Frigorífico Anglo en la ciudad Fray Bentos-Río Negro, representó uno de los pilares a nivel nacional e internacional. En el barrio Cerro de Montevideo se mantuvo una íntima relación con dicha industria desde sus inicios como villa, albergando saladeros primero y plantas frigoríficas después. Hacia 1945, funcionaban los frigoríficos Armour y Swift de capitales estadounidenses, el Frigorífico Nacional de carácter estatal y el Frigorífico Castro al otro lado del arroyo Pantanoso de capitales nacionales.

Era un sector productivo que implicaba una gran concentración de trabajadores y trabajadoras. Si bien la mayor parte eran varones, también trabajaban mujeres. Se desplegó un pujante y vigoroso movimiento obrero y trabajador en general y se desataron fuertes luchas, en las que los sindicatos de la Federación Autónoma de la Carne llevaban la punta de lanza de un colectivo más amplio, que integraba a otras organizaciones y vecinas/os del barrio.

En el Archivo de la Federación Autónoma de la Carne, entre otros documentos, se hallan ejemplares de periódicos editados tanto por la propia Federación, como por algunas de las organizaciones sindicales que la integraban. ${ }^{1}$

${ }^{1}$ El acceso al archivo de la Federación de la Carne se realizó por parte del Equipo de trabajo del Proyecto de investigación "El Cerro en los años sesenta, ¿̇barrio de trabajadores o comunidad obrera?” El Proyecto financiado por la CSIC I+D, es coordinado por el Dr. Rodolfo Porrini y 
Principalmente en el periódico iLucha! se plasmaron artículos que se detienen en consideraciones sobre "la mujer obrera." En abril de 1951, un pequeño anuncio convocaba: "Exhortamos a la mujer trabajadora de los frigoríficos a ocupar su puesto en la gran manifestación del $1^{0}$ de mayo." ${ }^{2}$ Resultan llamativas las permanentes alusiones a "colocar" a las mujeres trabajadoras u obreras, a que "ocupen" "su lugar" o "su puesto." En este artículo se intentará comprender y reflexionar acerca de algunos "lugares" que, según se desprende de esta fuente de prensa sindical de la industria de la carne, deben ocupar las mujeres en clave de roles de género y representaciones.

De la mano del movimiento feminista, la categoría de género ha transformado la comprensión de los procesos históricos, así como la forma de hacer historia ya que sitúa la construcción sociocultural de la diferencia entre los sexos como aspecto primario de la organización política, económica y cultural de la sociedad. Lo masculino y femenino se conforma como un sistema que impregna las relaciones sociales, la estructura y la organización social a tal punto que erróneamente se biologizan. 3

Las conformaciones sociales, según las diferentes épocas, han construido nociones desiguales y asimétricas de los roles empíricos -entendidos como el conjunto de actitudes, capacidades, expectativas y valores- que se asignan y deben ser asumidos por mujeres y varones. Al mismo tiempo, han elaborado representaciones que hablan de qué y cómo se entiende lo femenino, qué creencias y marcos ideológicos los sustentan y su abordaje permite desentrañar los procesos interpretativos y simbólicos, así como la producción de sentidos. 4

\footnotetext{
también está integrado por Lucía Siola, Francis Santana y Tania Rodríguez. Mi ingreso al equipo fue en marzo de 2018.

2 iLucha!, Montevideo, abril de 1951, p.8.

3 SCOTT, Joan, Género e Historia, México, Fondo de Cultura Económica, 2008. ARAÚJO, Ana María; BEHARES, Luis. E; SAPRIZA, Graciela, Género y sexualidad en el Uruguay, Montevideo, Ed. Trilce, 2001. LAMAS, Marta (comp.) El género. La construcción cultural de la diferencia sexual, México, UNAM, 1996.

4 HALPERIN, Paula; ACHA, Omar, "Historia de las mujeres e historia de género" en ACHA, Omar; HALPERIN, Paula (comp.), Cuerpos, géneros, identidades. Estudios de género en Argentina, Buenos Aires, Ediciones del Signo, 2000, p.16. También ver capítulo de LOBATO, Mirta "Representaciones del trabajo femenino" en LOBATO, Mirta. Historia de las trabajadoras en la Argentina (1869-1969), Buenos Aires, Ed. Edhasa, 2007.
} 
Este texto pretende observar esos roles y representaciones enfocándose en la organización y entramado cultural de la clase trabajadora. Algunas preguntas orientan el análisis: ¿cuáles son las representaciones de las mujeres obreras según estas publicaciones sindicales?, ¿qué roles les eran asignados?, y en el entendido de que el espacio sindical aboga por un mundo mejor, ¿qué alternativas o transformaciones se pueden encontrar en el plano discursivo?, ¿se interrogan, se intenta subvertir o se mantienen los pensamientos y prácticas tradicionales? En concreto, a través de la prensa sindical de la industria de la carne se observarán artículos que refieren a la mujer obrera/mujer trabajadora atendiendo a algunos roles y representaciones de género en torno a la maternidad y el trabajo de las mujeres, así como algunos preceptos morales que lo sustentan. Por otro lado, se abordarán las dificultades y las propuestas en torno al lugar de las mujeres en la vida sindical y las formas de su participación.

El periodo comprendido para el estudio está dado por la concentración de periódicos iLucha! recabados: son 17 números entre 1946 hasta 1952. Si bien la muestra recogida limita el estudio, también se presenta como una buena posibilidad de resignificar fenómenos sindicales y periodizaciones establecidas por la historiografía. 5 Habilita a ubicar a las mujeres y las relaciones de géneros en un contexto social y un espacio temporal acotado.

En Uruguay los estudios sobre la clase trabajadora se han enfocado en observar su conformación y principalmente las formas de agremiación, la diversidad y las disputas ideológicas, las formas de protesta, la historia de los derechos laborales o a clasificar los diferentes períodos. También emergió la historia de los sectores populares y más adelante, abordajes de la experiencia de la clase obrera, las condiciones de su existencia material, la importancia del lugar del trabajo, la vida cotidiana, la comunidad, la etnicidad, las simbologías y los rituales, incluso el tiempo libre.

En este marco, se intenta aportar a los estudios sobre trabajo y género, especialmente lo referido a sus interrelación y a la participación de las mujeres de la clase trabajadora en Uruguay, apostando a que la categoría de género no

5 Me refiero aquí al periodo comprendido por la acción de los "sindicatos autónomos" y la denominada lucha de los Gremios Solidarios que serán mencionadas más adelante. 
sólo sea "un conjunto de categorías sociales autoevidentes (los roles que tenían hombres y mujeres)", sino que también proporcione "un efecto crítico sobre la forma en que se concibe la historia del trabajo..."6 Una serie de estudios son antecedentes e inspiradores de este trabajo: particularmente los trabajos de Yamandú González Sierra por las discusiones que se suscitaron a fines del siglo XIX y principios del siglo XX en torno a los papeles sociales de las mujeres en la sociedad, entre ellos el valor productivo de su trabajo; de la historiadora Graciela Sapriza al investigar sobre la huelga de mujeres realizada en Juan Lacaze, de la historiadora argentina Mirta Lobato y del antropólogo uruguayo Javier Taks, vinculados a la historia de los frigoríficos, de las mujeres y el género, además de algunos valiosos indicios aportados por Juan Pablo Bonetti. ${ }^{7}$

\section{Lo que nos puede decir la prensa sindical frigorífica sobre las mujeres y el género en el mundo del trabajo.}

La prensa constituye una fuente y un objeto de estudio de primer orden cuando se hace historia. En concreto, las publicaciones realizadas desde sectores populares son primordiales porque recogen el testimonio de trabajadores y sus instituciones/organizaciones, tendiendo a una historia "...que recupere y restituya la memoria de aquellos sectores olvidados y silenciados."8 Por lo tanto, "su estudio es crucial en una historia social, cultural y política sensible a la experiencia de las clases trabajadoras."9

\footnotetext{
${ }^{6}$ SCOTT, Joan, Ob. Cit. P.79.

7 GONZÁLEZ SIERRA, Yamandú, Del hogar a la fábrica, ¿deshonra o virtud?, Montevideo, Ed. Nordan, 1994. SAPRIZA, Graciela. Los caminos de una ilusión. 1913: huelga de mujeres en Juan Lacaze, Montevideo, Ed. Fin de Siglo, 1993. De la misma historiadora también son de destacar "Identidades populares. La historia de un pueblo obrero (1890-1913)", en LULLE, Thierry; VARGAS, Pilar; ZAMUDIO, Lucero (dir.) Los usos de la historia de vida en las ciencias sociales I, Bolivia, Institut français d'études andines, Ed. Anthropos, 1998, e Hilamos una historia. La memoria sindical desde las mujeres, Montevideo, CIEDUR, 1989. LOBATO, Mirta, Historia de las trabajadoras...” Ob. Cit.; La prensa obrera. Buenos Aires y Montevideo 1890-1958, Buenos Aires, Ed. Edhasa, 2009; "Dentro y fuera del lugar. Carne, trabajo e identidades de género en Argentina" en SURIANO, Juan; SCHETTINI, Cristiana (comp.) Historias cruzadas. Diálogos historiográficos sobre el mundo del trabajo en Argentina y Brasil. Buenos Aires, Ed. Teseo, 2019.TAKS, Javier, "La Clase Trabajadora y las obreras del Anglo" en Revista ENCUENTROS No6, Montevideo, octubre. CEIL-CEIU/FHCE y FCU, 1999, BONETTI, Juan Pablo, La marcha del hambre. ¿Una historia enterrada, silenciada o escondida?, Montevideo, 2016

8 JUNG GARIBALDI, María Eugenia; RODRÍGUEZ DÍAZ, Universindo, "Importancia de la prensa sindical como fuente historiográfica" en Rodolfo PORRINI (comp.) Historia y memoria del mundo del trabajo, Montevideo, Imprenta Aragón, UdelaR, FHCE, CSIC, 2004. P.151.

9 LOBATO, Mirta, La prensa obrera...” Ob. Cit. P.10.
} 
Es un documento esencial teniendo en cuenta que era uno de los medios de comunicación posible, cotidianizado. Partidos y grupos políticos, asociaciones gremiales, estudiantiles, barriales, de inmigrantes y de sindicatos, sacaban periódicos, revistas, boletines y folletos, que podían variar en su periodicidad. En Uruguay, la prensa redactada por asalariados y asalariadas podía ser de una rama de la producción industrial o del sector servicios. ${ }^{10}$

Era el medio para expresar las aspiraciones de las organizaciones, para propagar reivindicaciones, denuncias, propuestas y formar opinión. Tenía un papel educativo y agitativo, ya que se intentaba instruir a los y las lectores y lectoras sobre las conductas y pensamientos considerados correctos. "Los periódicos gremiales tenían un sentido pedagógico y buscaban erradicar los males que introducía en las mentes y la cultura obrera el pensamiento burgués a través de los grandes diarios." 11 A través de la prensa se buscaba construir una sociedad opuesta a la capitalista. También era la herramienta para “...enfrentarse doctrinaria e ideológicamente con las clases dominantes y disputar a los grandes diarios de circulación masiva los lectores correspondientes a los estratos populares." $12 \mathrm{Si}$ bien estos periódicos nacen de organizaciones sindicales, igualmente constituyen una fuente de gran utilidad para conocer y reconstruir la vida, los pensamientos y las ideas, de un sector laboral de trabajadoras y trabajadores.

El marco cronológico establecido aquí se caracterizó por las implicancias mundiales de la posguerra y de la Guerra Fría, lo que en Uruguay significó la alineación de sus diferentes partidos y organizaciones sociales. A nivel económico hubo ciertos factores que favorecieron las ventajas comparativas de los productos latinoamericanos. ${ }^{13}$ Esta cierta "bonanza económica” y la política desarrollista del

\footnotetext{
${ }^{10}$ Referencias historiográficas sobre la prensa obrera, sindical y de izquierda, pueden encontrarse en ZUBILLAGA, Carlos; BALBIS, Jorge, Prensa obrera y obrerista (1875-1905), Historia del movimiento sindical uruguayo, Tomo 2, Montevideo, EBO, 1986. JUNG GARIBALDI, María Eugenia; RODRÍGUEZ DIAZ, Universindo, Ob. Cit.

${ }^{11}$ LOBATO, Mirta, La prensa obrera... Ob. Cit. P.10.

${ }^{12}$ LOBATO, Mirta, Ibídem. P.17. En iLucha! se pueden encontrar referencias en este sentido donde se realizan denuncias hacia Radio Carve o a otros diarios nacionales: iLucha!, Montevideo, marzo de 1951, p.1, "Prensa Mercenaria."

13 Los factores estarían dados por "los beneficios que dejaron nuestra producción agropecuaria y nuestro comercio exterior durante la Segunda Guerra Mundial, el período de reconstrucción y la posterior guerra de Corea...” NAHUM, Benjamín; COCCHI, Ângel; FREGA, Ana; TROCHÓN,
} 
neobatllismo que predominaba en la época, posibilitaron un importante aumento de la industrialización y por ende, del número de trabajadores y también de trabajadoras. ${ }^{14}$ Las transformaciones desarrolladas en el conjunto de la clase trabajadora en este período llevaron a denominarla "nueva clase trabajadora" y en cuanto a las especificidades sindicales, Alfredo Errandonea y Daniel Costábile utilizan la denominación de "sindicalismo dualista." 15

La ley de Consejo de Salarios, entre otras leyes laborales, ayudaron a impulsar la afiliación sindical, pero también a integrar a trabajadoras y trabajadores en las dinámicas estatales, además de canalizar la conflictividad por vías reglamentadas. Sin embargo, permanecían espacios y organizaciones e incluso prácticas sindicales de acción directa, autonomía, independencia y con capacidad movilizadora. Por todo ello, en el período comprendido aquí “...se procesó una intensa lucha intersindical que implicó un debate ideológico entre las tendencias, atravesado también por el contexto internacional."16 Quienes se disputaban la adhesión de las y los trabajadores eran socialistas, comunistas, "sindicalistas", “autónomos”, anarquistas, católicos, trostkistas y cristianos.

La Federación Autónoma de la Carne, como lo dice su nombre y como se han encargado de enfatizar sus integrantes y vecinas/os cerrenses en relatos que se rastrean hasta la actualidad, formaba parte de los "sindicatos autónomos." 17 De diversa y "ambigua” conformación ideológica, o "difícil de encasillar", el "sindicalismo autónomo" no ha sido objeto de profundos estudios. ${ }^{18}$ En este

Yvette, Crisis política y recuperación económica 1930-1958, Historia Uruguaya, Tomo 7, Montevideo, EBO, 1998. P.74.

14 Ibídem, p.120. El Censo Industrial de 1936 había relevado cerca de 80.000 obreros, mientras que en 1956 sobrepasaban los 150.ooo. Una completa síntesis de los estudios sobre el "importante empuje industrial" puede encontrarse en PORRINI, Rodolfo, La nueva clase trabajadora uruguaya (1940-1950), Montevideo, FHCE-UdelaR, 2005.

15 PORRINI, Rodolfo, La nueva clase... Ob. Cit. ERRANDONEA, Alfredo; COSTÁBILE, Daniel, Sindicato y sociedad en el Uruguay, Montevideo, FCU, 1969.

16 PORRINI, Rodolfo. La nueva clase... Ob. Cit. P.225.

${ }_{17}$ Los trabajos del historiador Rodolfo Porrini citados en este artículo abordan las diferentes expresiones sindicales de la época. Otro estudio relevante refiere a una de las luchas más significativas de este sector sindical: CORES, Hugo, Las luchas de los Gremios Solidarios (19471952): neo-batllismo, protesta social y Fuerzas Armadas, Montevideo, EBO, Editorial Compañero, 1989.

18 PORRINI, Rodolfo, "Clase obrera, sindicatos y Estado en el Uruguay de la expansión industrial (1936-1947)”, en Estudos Ibero-Americanos. PUCRS. v. XXIX. n. 2. 2003. P. 187. Hugo Cores afirma que los "sindicatos autónomos" estaban integrados por "grupos sindicalistas, anarcosindicalistas, anarquistas y marxistas independientes..." que criticaban "al reformismo 
sentido, lo que se analiza en el presente artículo pretende contribuir a echar luz sobre un segmento de su universo de ideas. Una mirada de género a la prensa sindical, en este caso, la que responde a un sector del sindicalismo autónomo, permitirá esclarecer las valoraciones, el panorama de roles, la división sexual del trabajo y nociones genéricas que se expresan en sus discursos. Atendiendo a lo literal, pero en particular a lo subyacente de lo dicho y de lo no dicho allí, a las ausencias y a los énfasis, se desprenden las temáticas que generaban inquietud, las ideas y los comportamientos que se alentaban, educaban, cuestionaban y las propuestas que por su importancia se publican y difunden. Siendo el pensamiento sindical parte de un universo de ideas que lo trascienden, la idea es atender las nociones que atravesaban al mundo de la clase trabajadora y desentrañar lo que constituía la mentalidad popular de una época.

\section{Muestra de la prensa sindical de la industria frigorífica.}

El 7 de enero de 1942 el conjunto de las diversas organizaciones o "entidades gremiales" de esa rama de la industria fundaron la Federación Obrera Autónoma de la Industria de la Carne y Afines (FOICA-A o FOAICA). ${ }^{19}$ A partir de diciembre de 1945 se comenzó a editar iLucha!..20 La cabecera del periódico ilustraba los principales símbolos del Cerro de Montevideo: el cerro y su faro, la playa, la chimenea, la planta industrial y las casas del barrio. (Imagen $\mathrm{N}^{\circ}{ }_{1}$ )

\footnotetext{
evolucionista del PS y al stalinismo del PC, desde el seno mismo del movimiento obrero." De esta forma "constituyeron el sector dotado de mayor vitalidad y espíritu combativo." En sus luchas "muy impregnadas de espontaneísmo e improvisación, aparece un cierto reverdecimiento de prácticas y concepciones de tipo 'sindicalista' y anarcosindicalista." CORES, Hugo, Ob. Cit. P.17 y 169.

19 En los Estatutos de la FOICA-A, se consigna que la Federación fue fundada “...por el personal obrero de los frigoríficos SWIFT y ARTIGAS de Montevideo, por los presentes estatutos adquiere el carácter de 'CENTRAL ADMINISTRATIVA' de los gremios obreros de esta RAMA de la industria y afines, con la aprobación y adhesión de las siguientes entidades gremiales: Sindicato Obrero del Frigorífico Swift, Sindicato Obrero del Frigorífico Artigas, Sindicato Obrero de Obreros y Obreras del Frigorífico Nacional, Sindicato Obrero del Frigorífico Anglo de Fray Bentos, Centro de Protección de Empleados y Obreros del Abasto y Sociedad de Carga y Descarga de los Frigoríficos.” (mayúsculas en el original)

20 El periódico constaba su sede social en Francia esq. Portugal, hasta que hacia fines de 1949 ya se encuentra en el lugar donde se mantiene en la actualidad, Grecia 3681.También existen escasos números de Lucha (sin signos de exclamación) del año 1970.
} 


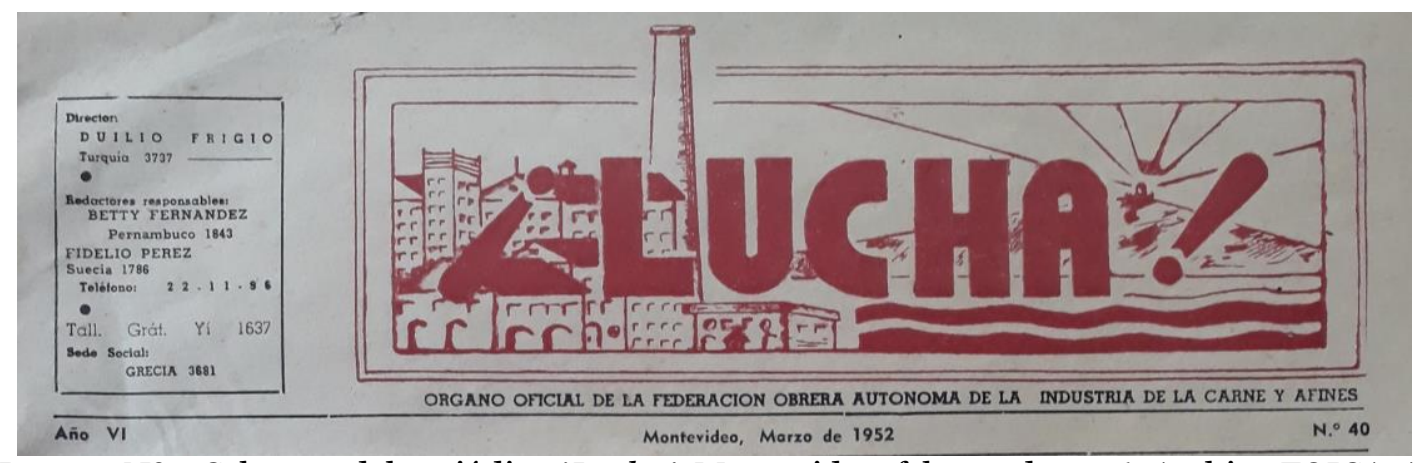

Imagen $\mathrm{N}^{0}{ }_{1}$. Cabecera del periódico iLucha!, Montevideo, febrero de 1946. Archivo FOICA-A.

Emancipación, era el Órgano del Sindicato de Obreros del Frigorífico Swift. ${ }^{21}$ (Imagen $\mathrm{N}^{\circ}{ }_{2}$ ) El único número de este periódico hallado en el archivo de la FOICA-A realiza una enfática defensa del federalismo como "sistema de organización (...) superior a cualquier otro de los existentes.”22

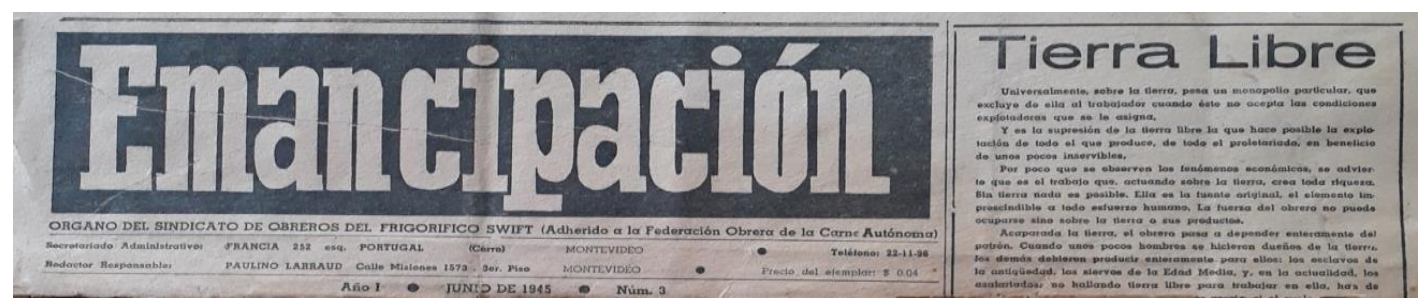

Imagen $\mathrm{N}^{\circ}$ 2. Cabecera del periódico Emancipación, Montevideo, junio de 1945. Archivo

FOICA-A.

Innovación, el Órgano del Sindicato de Obreros y Obreras del Frigorífico Nacional, surge en diciembre de 1944. (3 números, de 1948 y 1950). (Imagen $\left.\mathrm{N}^{\circ} 3\right)^{23}$ Según consta en Innovación, “...el $1^{\circ}$ de mayo de 1945 sale conjuntamente un número extraordinario de INNOVACIÓN fusionado a LA VOZ, órgano del Sindicato de Obreros y Obreras del Frigorífico Artigas." Se afirma que dicha edición en conjunto se desarrolló en algunos números más. ${ }^{24}$ Hasta el momento no he encontrado ningún ejemplar u otra referencia a este último periódico.

\footnotetext{
${ }^{21}$ Con sede en Francia 252 esq. Portugal.

${ }^{22}$ Emancipación, Montevideo, junio de 1945, p.1, "Nuestro concepto federalista." La declaración refiere a ciertas desavenencias que se suscitaron entre el Sindicato de Obreros del Frigorífico Swift y la FOICA-A.

23 Posteriormente, en 1965 cambia su nombre a Orientación. En el archivo de la FOICA-A se hallan tres números de 1965 .

24 Innovación. Montevideo, marzo 1948, p.1. "Innovación de nuevo en la brecha."
} 


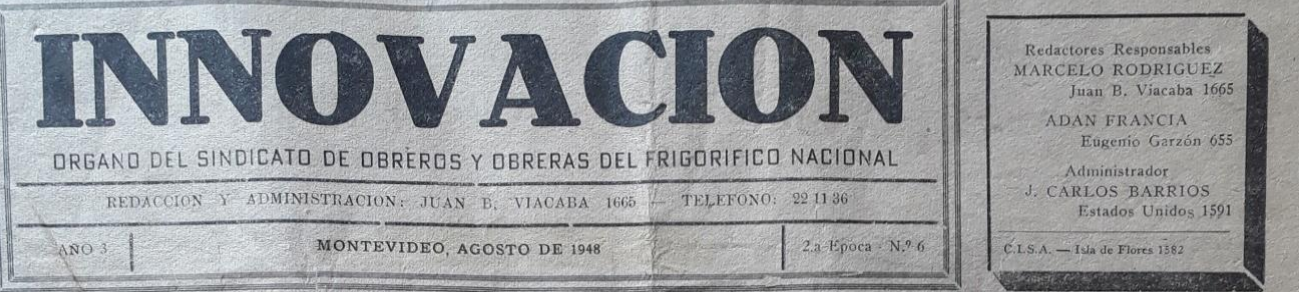

Imagen $\mathrm{N}^{\circ} 3$. Cabecera periódico Innovación, Montevideo, agosto de 1948. Archivo FOICA-A.

En aras de contribuir a completar el mapa de prensa del sector industrial de la carne, cabe indicar que en la Biblioteca Nacional se hallan ejemplares de $A S E I F$, Órgano Oficial de la Asociación de Supervisores y Empleados de la Industria Frigorífica, ubicado en Grecia 4255 esq. Japón (20 números entre 1948 y 1952). ${ }^{25}$ El material en su conjunto permite conocer el universo de ideas y prácticas que se llevaron adelante por trabajadoras y trabajadores organizados en este sector productivo. Constituye un desafío profundizar el abordaje de estas publicaciones en relación a estos mismos aspectos o a otros que son plasmados allí. Si bien se trabajará en base a iLucha!, según se considere pertinente se podrá complementar el análisis con pasajes de las demás publicaciones.

\title{
Maternidad, trabajo, respeto y moral.
}

En marzo de 1947 iLucha! publica el artículo "La Mujer Obrera”, bajo la firma de La Unión Obrera Swift, que comienza con la siguiente afirmación:

\begin{abstract}
"El hecho de que la mujer deba alquilar sus brazos para poder contribuir con el aporte de su esfuerzo al mantenimiento del hogar, no significa que ha descendido en su nivel moral. La mujer que trabaja en un establecimiento industrial o comercial obligada por las circunstancias o por las necesidades que han traido aparejada el desmedido afán de lucro de los comerciantes e industriales, es doblemente digna de admiración y respeto.” 26
\end{abstract}

El trabajo, aunque actividad fundamental, no es igualitaria en términos de género. Para las mujeres no es un derecho, sino que tiene carácter de obligación y es solo producto de la necesidad. Como señala la historiadora Dora Barrancos, se admitía “que las mujeres de los sectores obreros no tuvieran más remedio que salir a procurar ingresos para engrosar las retribuciones del varón productor,

${ }^{25}$ Además, la Unión Obrera de Rio Negro (UORN) del frigorífico Anglo, también integrante de la FOICA-A, publicaba el periódico Orientación.

26 iLucha!, Montevideo, abril de 1947, p.2, "La Mujer Obrera”, por la Unión Obrera Swift. 
pero solo por esa razón se consentía que las madres dejaran a los niños y desatendieran las tareas de la casa." ${ }^{27}$ Son las circunstancias o el afán de los industriales los que empujan a las mujeres a trabajar. Según lo constatado por Mirta Lobato, en los periódicos sindicales, las menciones sobre el trabajo femenino versaban alrededor de "la explotación de las mujeres como la más cruel expresión de la dominación capitalista...” ${ }^{28} \mathrm{Al}$ mismo tiempo, el trabajo realizado por las mujeres es valorado como un “aporte”, una contribución de índole secundaria. El hecho de explicitar con tono pedagógico el respeto que merece toda mujer obligada a trabajar, demuestra las nociones que existían en la clase trabajadora, que la publicación sindical intenta modificar. Asimismo, parece que las receptoras del mensaje son aquellas madres abnegadas de familia constituida, ante lo cual surge la pregunta dlas que no cumplen con los requisitos que allí se mencionan, son objeto de la misma admiración y respeto?

Luego indica, "Que la madre deba dejar a sus hijitos solos en el hogar o a cuidado de terceros (...) demuestra concluyentemente el enorme sacrificio a que están sometidas...” Estará “durante todas las horas del día preocupada en sus pequeños...” La alimentación, la educación y el cuidado “...nunca por muy bien que se les atienda lo hará como lo haría su propia madre." El trabajo extradoméstico significa para las mujeres un sacrificio porque su papel esencial es el cuidado de los hijos es una función inherente al sexo femenino. Su labor es exclusiva y excluyente. La fábrica representa “...un jirón del hogar abandonado”29, un hogar corroído. No existe la misma valoración con el vínculo que el trabajo deshace entre hijos/hijas y padres, ellos no están "todas las horas del día” preocupados por "sus pequeños."

A continuación, se denuncia "El trato que se le dispensa a nuestras compañeras de labor, con que desparpajo y desconsideración se les trata”. Se refieren en concreto a que:

"El tuteo por parte de los capataces, empleados u obreros debe desaparecer. Es necesario que cuando un hombre dirija la palabra a una mujer dentro del

\footnotetext{
27 BARRANCOS, DORA, Mujeres en la sociedad argentina. Una historia de cinco siglos. Buenos Aires, Ed. Sudamericana, 2007. P.148.

${ }^{28}$ LOBATO, Mirta. Historia de las trabajadoras... Ob. Cit. P.82.

29 Ibídem. P.81.
} 
establecimiento lo haga con respeto, llamándole como corresponde, señora o señorita y no como se hace en la actualidad, como si dirigieran la palabra a una vulgar mujerzuela o prostituta. No puede ni debe confundirse nunca un establecimiento industrial con un cabaret. No hay que confundir una sección o departamento de los frigoríficos con un prostíbulo.”3o

Muchos sentidos y valores se desprenden de este párrafo. Se explicitan y se evidencian públicamente conflictos de índole sexual entre varones y mujeres que trabajan en el mismo espacio. En concreto los frigoríficos suponían lugares de labor de fuerte presencia y jerarquía masculina, donde se destacaban sus destrezas asociadas a la fuerza, en detrimento de las habilidades de las mujeres. ${ }^{31}$ La jerarquía que se atribuía a los varones en los procesos de trabajo, en los cargos de responsabilidad y en los salarios, se traducía en gestos y prácticas que degradaban aún más el lugar de subordinación de las mujeres.

Se afirma sin rodeos que hay dos clases de mujeres, unas a las que se les debe respeto y otras a las que no, estableciéndose una “...oposición entre labores virtuosas y viciosas...", ${ }^{2}$ sin reparar en la conducta de los varones como responsables de la existencia de las "vulgares mujerzuelas" o "prostitutas." El tono de las alusiones y comparaciones con el cabaret o el prostíbulo demuestran la normalidad que esos espacios constituían para los varones y las prolongaciones que realizaban estos hacia todas las mujeres. Generando esto que la línea divisoria entre "virtuosas” y “viciosas” sea frágil, casi inexistente. Como señala la historiadora Miren Llona, "La figura de la prostituta se constituyó en un elemento simbólico de carácter activo en la conformación de la identidad de las mujeres de las clases trabajadoras, y trasladó su carga de violencia simbólica y de misoginia sobre ellas." Como en otros medios obreros, en el Cerro, las mujeres tuvieron "que hacer frente, no sólo a sus difíciles condiciones de existencia, sino a ese imaginario social, a esa corriente general de identificación de la mujer pobre con la mujer prostituta." 33 Tan habitual como despreciable, la prostitución se

${ }^{30}$ Ibídem.

${ }^{31}$ Los varones monopolizaban las tareas consideradas de "fuerza" y las mujeres destacaban en secciones "manuales" (conservas, hojalatería, tripería, costura) Además del estudio de TAKS, Javier. Ob. Cit., entre los trabajos de Mirta LOBATO, ver especialmente "Dentro y fuera del lugar..." Ob. Cit.

${ }^{32}$ LOBATO, Mirta, Historia de las trabajadoras... Ob. Cit. P. 296.

33 LLONA, Miren, "La prostitución y a identidad de la clase obrera en el tránsito del siglo XIX al XX. Un análisis de género a la obra literaria de Julián Zugazagoitia”, en Revista Historia 
constituyó como una “institución-válvula" admitida y tolerada porque "contribuía a preservar un orden matrimonial construido sobre una moral sexual rigurosa en la que las esposas e hijas de los hogares decentes debían ser mantenidas en una virtual invalidez sexual."34

En este contexto, la noción de respeto pasa por cómo los varones dirigen la palabra a las mujeres dentro del ámbito laboral, cuando es posible suponer -a través del propio texto-, que los abusos iban mucho más allá de un simple tuteo. El artículo admite que los victimarios son tanto capataces como empleados y compañeros obreros, sin diferencias.

Se expresan los comportamientos que cada género puede y debe corregir. Hacia los varones se advierte que "en cada oportunidad que dirijáis la palabra a una compañera, pensad que os dirigís a la madre, hermana o esposa de otro trabajador." De esta forma, el respeto no corresponde a las mujeres en su condición de sujetos y/o personas, sino a su circunstancia de parentesco con los varones. Por otro lado, se exhorta a las trabajadoras a exigir "que se os trate con el debido respeto, considerad que si permitís el manoseo de hecho o de palabra por cualquier persona, se os rebaja no solo en vuestra condición de mujer, sino, en el propio honor." Agrega más adelante, "No olvidéis trabajadoras que vosotras sois las guardianes del honor de vuestros esposos e hijos.”

El hilo argumental del discurso devela que las mujeres son las únicas responsables del cuidado del hogar y sufren al abandonarlo, por el sacrificio que deben realizar al salir de sus casas a trabajar en lugares donde pueden ser o son abusadas por cualquiera de los integrantes varones que allí se encuentran. Se las entrevé como culpables y no solo culpables ante sí, sino además y muy por encima de todo, garantes del honor de la familia. En fin, un laberinto sin escapatoria de culpas y remordimientos. Se es culpable de antemano, antes de que se pueda demostrar incluso lo contrario. A los varones solo les cabe la responsabilidad de

Contemporánea 33, 2006. P.727. Este artículo expone el estudio sobre la prostitución en el medio minero vizcaíno.

34 TROCHÓN, Yvette, “De grelas, cafishios y piringundines...” en BARRÁN, José Pedro; CAETANO, Gerardo PORZECANSKI, Teresa (dirs.), Historias de la vida privada en el Uruguay, Tomo 3, Individuos y soledades (1920-199o) Montevideo. Ed. Taurus. 1998. P.67. Yamandú González Sierra, confirma estas nociones para el período abordado en su investigación en relación a la realidad uruguaya. GONZÁLEZ SIERRA, Yamandú, Ob. Cit. 
no tutear a las mujeres de "bien", de no prolongar el trato que habitualmente dispensan en los prostíbulos hacia las mujeres que trabajan en la fábrica. Las prostitutas sí constituyen objeto de irrespetuosidades, son seres que, si bien existen por la acción de los varones, se merecen los mayores desprecios y ultrajes.

Las alusiones a la moral constituyen un tema clave en los sectores populares o trabajadores y merecen un estudio específico ya que permiten descubrir los sistemas de valores, las normas culturales que se alentaban, además de mostrar a la moral como fuerza de control social. La moral de las mujeres corría riesgo permanente. El solo hecho de "salir a trabajar solía ir acompañado de una sombra, de una insidiosa duda sobre la integridad moral." 35

Incluso la salubridad contiene un componente moral que se pretende traducir en legislación laboral. En un artículo del periódico Innovación de 1948 sobre un "Proyecto de Trabajos Insalubres", se ataca la problemática a través de afirmaciones fuertemente taxativas. ${ }^{36} \mathrm{El}$ "trabajo insalubre" tenía consideraciones diferenciales de sexo/género. El artículo $4^{\circ}$ decreta con énfasis, "Queda absolutamente prohibido el trabajo nocturno de la mujer en las industrias insalubres." Nada más se expresa en este artículo, ni razones, ni descripciones, por lo que puede comprenderse como una obviedad el hecho de que es imposible que las mujeres trabajen en horarios nocturnos. La insalubridad nocturna es apta para los varones, no así para las mujeres. El espacio vital admitido para ellas se topa con el límite de la noche, momento en el que deben estar atendiendo su hogar y donde el riesgo radica en los abusos que pueden cometer los varones. 37

$\mathrm{El}$ artículo $12^{\circ}$ sobre "Salud moral de la mujer" afirma que "Las mujeres menores de 18 años no podrán realizar, en ningún caso tareas que comprometan su salud moral. Ninguna razón de orden técnico será suficiente para derogar esta disposición". No se precisa qué se entiende por "salud moral", no se brindan indicios de cuáles son las tareas que la comprometen. Son menciones realizadas

35 BARRANCOS, Dora "Moral sexual, sexualidad y mujeres trabajadoras en el período de entreguerras", en DEVOTO, Fernando; MADERO, Mirta (dirs.) Historia de la vida privada en la Argentina. Tomo III. Buenos Aires, Ed. Taurus, 1999. P. 206.

${ }^{36}$ Innovación, Montevideo, agosto de 1948, p.2, "Proyecto de Trabajos Insalubres."

${ }_{37}$ El trabajo nocturno de las mujeres era motivo de rechazo desde tiempo atrás. Ver LOBATO, Mirta, "Historia de las trabajadoras..." Ob. Cit. 210. 
con un halo de misterio pero que sugieren ser conocidas por todas y todos, un secreto a voces, una obviedad producto de la naturaleza humana. Se puede inferir que la salud moral está relacionada aquí también a la moral sexual. El historiador José Pedro Barrán verificaba que los asuntos relativos a la sexualidad, en muchas ocasiones se daban por sobreentendidos, aparecían con lenguaje velado, o "asomaba permanentemente en el silencio y el eufemismo..."38

La moral proletaria acorrala de culpas a las mujeres y es altamente permisiva con los varones. Una doble moral que se desdobla en tensiones persistentes entre honra/deshonra, vicio/virtud y que no reconoce las múltiples explotaciones a las que las mujeres se ven expuestas: económica, sexual, jurídica y también moral.

\section{La vuelta al hogar}

En el periodo comprendido aquí se crearon diversas leyes y otras reglamentaciones laborales que ampliaban los derechos a una importante porción del mundo del trabajo. ${ }^{39}$ Las publicaciones sindicales de la industria frigorífica, tienen artículos donde se exaltaba la organización gremial, subrayando la importancia de las leyes aprobadas gracias a los esfuerzos sindicales, se brindaba una postura crítica en relación a la reglamentación de los sindicatos e incluso, se enviaban cartas dirigidas al presidente Luis Batlle Berres en su periodo de gobierno.

Hacia 1950, en iLucha! aparecen artículos, anuncios y menciones a un Comité Femenino Pro Jubilación de la Mujer a los 25 años de trabajo.40 Incluso

${ }^{8}$ BARRÁN, José Pedro, "Historia de la sensibilidad en el Uruguay. La cultura 'bárbara'. El disciplinamiento.” Montevideo, EBO, 2017. Pp. 332-333.

39 Además de los Consejos de Salarios (1943), también se sancionaron -entre otras- la ley de Asignaciones Familiares; ley de Indemnización por despido (1944), el Estatuto del Trabajador Rural (1946); la indemnización por despido a enfermos y trabajadoras grávidas (1950), el salario por maternidad (1958). Sobre la legislación que implicaba a las mujeres, uno de los trabajos es el de RODRÍGUEZ VILLAMIL, Silvia; SAPRIZA, Graciela, Mujer, Estado y Política en el Uruguay del siglo XX, Montevideo, EBO, 1984.

$4^{4}$ En otros diarios de plaza también se encuentra al Comité Femenino en diversas acciones tendientes a conseguir su objetivo. Acción consta entre "sus actividades entusiastas y tenaces", una entrevista que el Comité mantuvo con el entonces Presidente de la Cámara de Diputados, Arturo Lezama (Montevideo, 21 de abril de 1951, p.3, “Jubilación Femenina.”). También consigna el apoyo que el mismo diario brinda a la organización (Acción, Montevideo, 17 de abril de 1951, p.3, "Jubilación femenina"). El 28 de abril de 1952, Acción y La Mañana, informan sobre una 
se exhorta a "todas las trabajadoras de la industria frigorífica..." a que "estén presentes" en una reunión a realizarse en la Sede de la FOICA-A. ${ }^{41}$ El reclamo de rebajar la cantidad de años requeridos para que las mujeres accedan a la jubilación es parte de la plataforma de reivindicaciones de la FOICA-A en ocasión de las manifestaciones del $1^{\circ}$ de mayo de $1951.4^{2}$

Es de destacar que la Federación Autónoma de la Carne abogaba por 20 años de trabajo para las mujeres. En marzo de 1951 se brindan argumentos a favor de tal iniciativa. 43 "La situación de la mujer que trabaja, se ha repetido hasta el cansancio (...) es muy distinta a la del hombre", éste "una vez completadas las horas de labor diaria, ve, por así decir, terminada su labor para consigo mismo y para con los suyos..." Se reconoce que, por el contrario, "la mujer comienza un nuevo ciclo de su labor, siendo esta de ahora, tanto, o más agotadora que la que había terminado ya." Se calcula que con esa propuesta, la mujer llegaría a la jubilación con aproximadamente 40 años y "recién entonces podría ATENDER su hogar como todo hogar se lo merece." (mayúsculas en el original) En forma de pregunta retórica, se asevera que esa edad es demasiado tarde para "poder ser realmente ama de casa, y gozar de todos los derechos a que la naturaleza le ha hecho acreedora...”

El trabajo reproductivo es el único al que las mujeres tienen derecho, es una especie de premio al cual las mujeres se hacen "acreedoras", pero es un derecho enraizado en supuestos de naturaleza biológica. Es imperioso devolver a la mujer a "su" lugar y reparar el daño perpetrado por el inhumano sistema. No existen planteamientos de co-responsabilidad genérica, ni mínimos cuestionamientos o intenciones transformadoras de esa realidad. La Federación de la Carne, redobla la propuesta del Comité Femenino, abogando por disminuir aún más la vida útil de las mujeres en el trabajo extradoméstico.

\footnotetext{
"entrevista con los representantes de la prensa" donde el Comité expresa una suerte de balance y perspectivas de acción.

41 También aparece el detalle de la integración de la Comisión del Comité Femenino, contabilizándose un total de 19 mujeres. iLucha!, Montevideo, abril de 1950, p.14, "Visita de la Federación", "Comisión del Comité Femenino" y "Comité Femenino."

${ }^{42}$ Acción. Montevideo, 28 de abril de 1951, p.2, "Preparan la manifestación de Trabajadores para el $1^{\circ}$ de Mayo."

43iLucha!, Montevideo, marzo de 1951, p.7, "Sobre la jubilación de la mujer”.
} 


\section{La vida sindical}

En el segundo número de iLucha!, en el año 1946, Humberto Gómez escribe que "colocar a la mujer obrera en la vida sindical es urgente problema..." Este y otros artículos de iLucha! dan cuenta del interés de carácter urgente de incorporar a las mujeres en la dinámica y lucha sindical.

\footnotetext{
"Profundos anacronismos la inhabilitan en la lucha gremial. Prejuicio de sexo, falso prurito, en un ambiente de asfixiantes debilidades humanas, han convertido a nuestras compañeras de trabajo en un objeto demasiado frágil para la vida de lucha que exige su condición de obreras". 44
}

Se considera que en el mundo obrero persisten pensamientos de otras épocas que imposibilitan la participación de las mujeres y que eso las hace débiles para lo que exige la lucha sindical. Esta especie de diagnóstico también declara que la mujer en los sindicatos “...muchas veces solo encuentra un hijo del mismo ambiente burgués e inmoral que la hunde más y más en el oprobio de una vida de explotadas...”, por lo que responsabiliza al pensamiento hegemónico burgués de colarse en los pensamientos obreros generando que se reproduzcan conductas ajenas a su clase.

Con la intención de atacar esa realidad, se exhorta a los "compañeros" a que “...cuando venga a la organización una obrera, mirémosla como tal, para que adquiera confianza en sí misma...” Más aún, "seamos suficientemente delicados con este ser nervioso que solo espera la mano fraternal y honrada de un auténtico hermano de clase para ocupar su puesto dentro del sindicato sin menoscabo de su moral como sucede muchas veces.” El fin tan deseado y necesario de que las mujeres ocupen un lugar en el sindicato, se conseguiría con una batería de tácticas: delicadeza, mano fraternal y honrada. Estas posturas no son parte de un horizonte de transformación de la vida cultural cotidiana de la clase trabajadora, sino que los varones deben adoptarlas de forma artificial solamente en el sindicato, son una pose aparente. La intención es utilitaria, no se propone transformar las dinámicas machistas sindicales -y otras- como un fin en sí

44 iLucha!, Montevideo, enero 1946, p.1, "La mujer obrera y la organización gremial." Humberto Gómez era un reconocido dirigente sindical del Frigorífico Nacional y militante del Partido Socialista. 
mismo, sino para darle cabida o "lugar" a las mujeres obreras. El verbo "colocar" utilizado en distintas ocasiones, hace pensar en una operación calculada.

Las características del carácter de varones y mujeres no son producto de condicionamientos histórico-culturales, sino que son naturales. La naturaleza no es cuestionada, al contrario, es perpetuada. No se visualizan otras formas de sujeto y sujeta histórica. Se acepta un "destino" natural que oprime las capacidades de las mujeres y ensalza las de los varones. Las mujeres son un "ser nervioso", "dueñas de los más delicados sentimientos del amor humano", mientras que los varones son el sexo fuerte.

Al mes siguiente, en febrero de 1946 bajo la firma de Zulma M. de Brun aparece el artículo "La mujer debe cooperar." 45 Es una especie de pequeño alegato donde se exponen las razones por las cuales "es deber de toda obrera organizada, luchar por nuestro Sindicato, y, así, siempre unidos, tanto el hombre como la mujer, debemos luchar para lograr nuestros anhelos de justicia y reivindicación." El mismo carácter secundario que se brinda al trabajo de las mujeres, también es el que se espera en la vida sindical, ellas deben "cooperar" o "colaborar" unidas a los varones.

En diciembre de 1950, ocupando una hoja completa y otro espacio posterior, iLucha! publica el artículo "La Mujer en la lucha Sindical", que si bien no está firmado parece ser escrito por una o varias mujeres. ${ }^{46}$ Comienza asegurando que las mujeres no intervienen en la lucha sindical y que ese "alejamiento de los asuntos gremiales es producto de distintos factores..." Reconoce que "cuántas veces hemos sentido decir a nuestras propias compañeras: 'Yo tengo que atender mi casa, tengo tal o cual ocupación, y no puedo dedicarme a trabajar por mi organización." La nociones de "doble explotación" o "doble jornada" que atienden a visualizar que las mujeres, además de cumplir el trabajo de doméstico, agregan el trabajo asalariado fuera del

\footnotetext{
45 El artículo de iLucha!, Montevideo, febrero de 1946, p.2, "La mujer debe cooperar", es firmado por "Z. M de B", y en la siguiente página 3, el pequeño artículo "Nota de estímulo" es escrito por Zulma M. de Brun, lo que hace inferir que sea ella la autora de ambos escritos.

46 iLucha!, Montevideo, diciembre de 1950, p.6 y 8, "La mujer en la lucha sindical.” El artículo es narrado desde la primera persona del plural, "nosotras."
} 
hogar, 47 son esbozadas -solamente en este artículo-, de forma limitada, tangencial y como pretexto, o sea, como si fuese un motivo sin consistencia que se alega para no realizar la actividad sindical. No se le brinda la categoría de trabajo, no se la toma con el rigor pertinente.

Más adelante, señalando los beneficios obtenidos a través de la lucha, se pregunta, "Y ¿qué papel hemos jugado nosotras, las mujeres, en la obtención de esas ventajas? Casi nulo.” En este caso como en otros, las mujeres son cuestionadas por su apatía y pasividad en relación a cuestiones sindicales, mientras que las causas vinculadas a las tareas de reproducción de la vida son vistas como excusas. ${ }^{8}$ Se realizan exhortaciones expresamente dirigidas: “...es preciso que tu, trabajadora, sacando fuerzas de flaqueza, contribuyas con tu deseo de vivir una vida mejor, con tu energía y entusiasmo. Es preciso que leas, que te instruyas, que te eduques, que pienses alto y sientas hondo." 49 Existe una clara intención de alentar en tono de arenga a que las mujeres venzan el supuesto desinterés, mientras no se señalan cuestiones similares sobre los varones.

Se impone a las mujeres obreras asumir lo que puede denominarse como "triple jornada" ${ }^{0}$ al añadir en su vida cotidiana la participación sindical. Los varones "cuentan con una infraestructura doméstica" que les permite dedicarse

\footnotetext{
47 La "doble explotación" ha sido denunciada por algunos feminismos desde finales del siglo XIX, mientras que "la doble jornada" es de elaboración posterior. Ver entre otros: AMORÓS, Celia, Tiempo de Feminismo. Sobre feminismo, proyecto ilustrado y posmodemidad, Madrid, Ed. Cátedra, 1997. BORDERÍAS; Cristina CARRASCO, Cristina; ALEMANY, Carme, Las mujeres y el trabajo. Rupturas conceptuales, Barcelona, Ed. Icaria, 1994. FEDERICI, Silvia, Revolución en punto cero: trabajo doméstico, reproducción y luchas feministas. Traficantes de sueños, 2013. CUADRO CAWEN, Inés, Feminismos y política en el Uruguay del Novecientos (1906-1932). Internacionalismo, culturas políticas e identidades de género, Montevideo, AUDHI-EBO, 2018. 48 “...respecto de la mujer obrera, se sostenía ampliamente una concepción que subrayaba su falta de interés en integrarse a las organizaciones sindicales." D'ANTONIO, Débora y ACHA, Omar, "La clase obrera 'invisible': imágenes y participación sindical de las obreras a mediados de la década de 1930 en Argentina”, en ACHA, Omar; HALPERIN, Paula (comp.), Ob. Cit. P. 243.

49 iLucha!, Montevideo, diciembre de 1950, p.6 y 8, "La mujer en la lucha sindical."

$5^{\circ}$ En este sentido resultan muy sugerentes algunos trabajos que proponen esta noción a partir de amplias referencias de estudios en los cuales se sustentan: SAGASTIZABAL, Marina; LEGARRETA, Matxalen, "La "triple presencia-ausencia": una propuesta para el estudio del trabajo doméstico-familiar, el trabajo remunerado y la participación sociopolítica”, en Papeles del CEIC, vol. 2016/1, $\mathrm{n}^{0}$ 151, CEIC (Centro de Estudios sobre la Identidad Colectiva), Universidad del País Vasco. SAGASTIZABAL, Marina, "Vivencias del tiempo social: compaginar la participación política, el cuidado y el empleo", en ARAÚJO, E.; DUQUE, E.; FRANCH, M.; DURAN, J. (eds.) Tempos Sociais e o Mundo Contemporâneo - As crises, As Fases e as Ruturas Centro de Estudos de Comunicação e Sociedade, Universidade do Minho. 2014. La tercera jornada estaría dada por la participación sociopolítica que cumplen las mujeres en tanto ciudadanas, militantes o vecinas barriales.
} 
en forma exclusiva al trabajo, a la política y otras actividades, "mientras que para las mujeres es muy difícil poder compatibilizar el trabajo asalariado con la participación política, ya que esto supondría una triple carga de trabajo...” ${ }^{11} \mathrm{La}$ participación sindical se constituye así como otro ámbito sujeto a consideraciones y sentidos morales, ya que las mujeres serán objeto de juicios en relación a las expectativas y obligaciones que se les adjudican.

Además, en el mismo artículo, a través de una pregunta, se brindan indicios sobre las incómodas sensaciones que producía en las mujeres el espacio del local sindical:

\begin{abstract}
“ipor qué hemos de sentirnos disminuidas, o [sic] opacadas al entrar a nuestra casa sindical, para llevar nuestra colaboración, que siempre ha de ser apreciada, principalmente en lo que se refiere a los problemas que conciernen a nuestro sexo, muchos de los cuales permanecen sin solución, debido, precisamente, a nuestra apatía a su respecto?” ${ }^{2}$
\end{abstract}

En suma, en el periodo abarcado se registra un intento de integrar a las mujeres en la vida sindical, pero sin modificar la situación en los hogares, ni los fundamentos patriarcales de las organizaciones sindicales, ni las consideraciones que se tienen sobre el carácter de varones y mujeres. Ellas deben continuar "atendiendo" la casa, trabajar fuera de sus hogares cargando con la culpa de abandonar a sus hijos/as, y a partir de ahora, colaborar con la lucha sindical modificando su "apatía", con entusiasmo, estudiando, venciendo falsas/fantasiosas/erróneas percepciones de subestimación de su participación.

Si de lugares a ocupar en los sindicatos se trata, a través de los ejemplares de iLucha! se pueden realizar algunas constataciones. Las diferentes listas a las comisiones directivas y administrativas de las diferentes entidades gremiales y de la propia FOICA, tenían muy escasa, o casi nula integración de mujeres, casi siempre en calidad de suplentes o de vocales. Tengamos en cuenta que varias de esas listas, por ejemplo, las que se presentaban a la directiva de la FOICA-A, podían estar integradas por treinta o más personas entre Comisión Administrativa, Comisión Fiscal y Junta Electoral. Veamos algunos ejemplos. En

${ }^{51}$ SAGASTIZABAL, Marina, "Vivencias del tiempo social...” Ob. Cit. P. 223.

${ }^{52}$ iLucha!, Montevideo, diciembre de 1950, p.6 y 8, Ob. Cit. 
ocasión de las elecciones para la Comisión Administrativa de la de la FOICA-A en octubre de 1948, se presentaron tres listas. Solo en la lista 1 con el lema "Federación Autónoma de la Carne" aparece una mujer como suplente para la Comisión Fiscal, Pilar Marín, del Frigorífico Nacional.53 En 1949 se presentaron dos listas a las elecciones para la Comisión que conduciría al Sindicato Unión Obrera Swift. En la lista $\mathrm{N}^{\circ} 3$ "Todo por la unidad", aparece como suplente María L. de Sabatobich de la sección Playa Vacuno y en la lista $\mathrm{N}_{2}^{\circ}$, "Por una superación sindical”, se encuentra a María A. Nuttes de la sección Especialidad como titular vocal, Angélica S. Puentes de la sección Picada como suplente vocal y Petrona M. de Guevara de la sección Especialidad, como suplente para la Comisión Fiscal.54 Entre las tres listas presentadas para la Comisión del Sindicato Artigas de 1949, solo aparecen dos mujeres en calidad de suplentes en una de las listas. 55

Hacia 1950, las Sub Comisiones de la FOICA-A están integradas amplia y mayoritariamente por de varones. ${ }^{6}$ La Sub Comisión de Arte y Cultura se propuso iniciar un "vasto plan de cultura" para que el hombre, el niño y la mujer tuviesen "una escuela de capacitación en el orden general de la cultura", a través de un plan de trabajo donde uno de los cuatro puntos propuestos era el "plan de enseñanza de labores domésticas." 57 Así planteado -no se encontraron otras referencias-, parecería que en el ámbito de esa Comisión las labores domésticas asomaron como una arista de la cultura que debía ser instruida a todas las personas, lo que hablaría de la preocupación por ampliar el horizonte genérico de ese espacio.

Las fotografías de las diferentes Comisiones sindicales que aparecen en algunos números de la publicación, evidencian la total ausencia de mujeres. Sí es posible encontrarlas en las fotografías de asambleas, que si bien no son muchas,

\footnotetext{
53 iLucha!, Montevideo, octubre de 1948, p.8, "Elecciones."

54 iLucha!, Montevideo, enero de 1949, p.5, "Elecciones en la Unión Obrera Swift."

55 iLucha!, Montevideo, enero de 1949, p.6, "Elecciones para cambio de Comisión del sindicato Artigas."

${ }^{56}$ En Prensa y Propaganda de once integrantes, dos son mujeres (Julia Sauchenko y Ada Aguirre), al inicio de la comisión Pro Sede Propia, existían por lo menos dos mujeres (Zulma Araújo y Petrona Guevara), pero luego fue integrada solo por varones. En Arte y Cultura, de ocho personas, existían tres mujeres (Irma de Leite, Zulma Galván, Ada Aguirre). (iLucha!, Montevideo, diciembre 1950, p.4, "Nuevas Sub Comisiones.")

57iLucha!, Montevideo, diciembre 1950, p.5, "Sub Comisión de Arte y Cultura."
} 
una de ellas resulta llamativa. Es una asamblea de obreros y obreras del Frigorífico Nacional realizada en el cine Edén del Cerro, el día 30 de enero de 1946. ${ }^{8}$ Como puede apreciarse en la imagen $\mathrm{N}^{\circ} 4$, fue una muy numerosa asamblea, a sala colmada. A juzgar por las miradas y otros gestos -varones en las filas superiores que alzan sus puños- que se dirigen expresamente a la cámara, fue una fotografía preparada, o sea, la asamblea en su conjunto sabía que se estaba tomando. La mayor parte de las personas son varones. En la primera fila, de forma muy visible, se ubican nueve mujeres (incluso la primera de ellas en el margen izquierdo está acompañada por un niño). Esta disposición en el conjunto de la fotografía de la asamblea atrapa la atención, parecen estar colocadas en la escena de forma artificiosa. Con una clara intención de mostrarse o ser mostradas en el ámbito público.

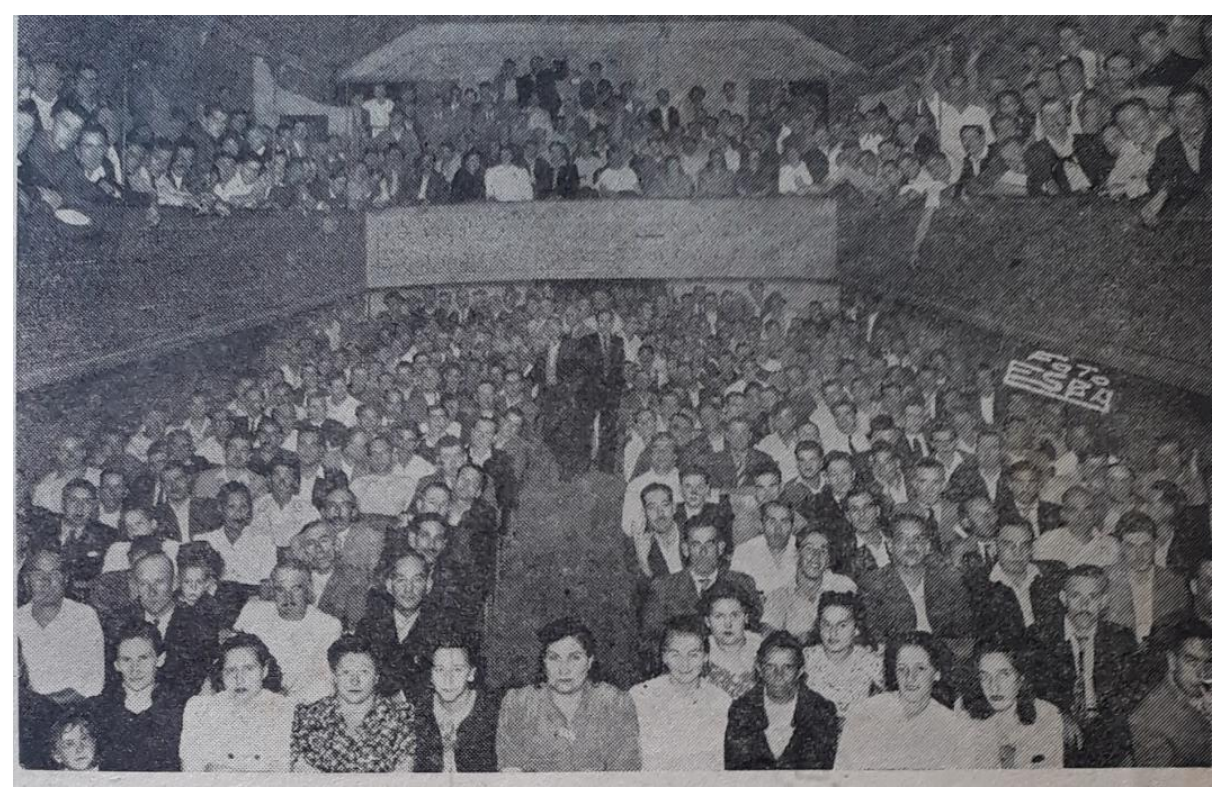

Imagen $\mathrm{N}^{\circ} 4$. Asamblea de obreros y obreras del Frigorífico Nacional. iLucha!, Montevideo, febrero de 1946, p.5. Archivo FOICA-A

La gran mayoría de los artículos de personas - no de organizaciones- en iLucha!, son firmados por varones. Varios de los artículos escritos por mujeres refieren a aspectos de la vida cotidiana 59 o son avisos de agradecimientos en relación a gestos de solidaridad sindicales. ${ }^{60}$ Otra nota resulta llamativa. Erika

\footnotetext{
${ }^{8} \mathrm{El}$ cine Edén se ubicaba en la calle Viacaba 1833 entre Bogotá y Portugal.

59 iLucha!, Montevideo, febrero de 1946, p.5 y 6, "El costo de la vida,” por Elida I.R de González. 6o Por ejemplo, en 1950 Delia Cóppola de Del Campo a través de una nota dirigida a la FOICA-A, agradece a "los obreros y empleados del Frigorífico Swift" por "la solidaridad moral y física" que
} 
Heizmann, hace público el agradecimiento a la Comisión de la FOICA-A por haber resuelto "el conflicto planteado entre la compañía Artigas y yo, y que afectaba mi buen nombre y conducta." ${ }^{1}$

Mirta Lobato señala que, "aunque se publicaban notas escritas por mujeres, la prensa gremial fue el resultado de una sociabilidad política articulada alrededor de los modos de sentir y expresarse de los varones."62 La contribución femenina fue mínima. En cuanto a la redacción responsable de los diarios, los dos números de 1952 que se hallaron, tiene a Betty Fernández. ${ }^{63}$ Es de destacar que uno de los sindicatos se haya denominado "Obreros y Obreras del Frigorífico Nacional."

En fin, la preocupación manifestada en diversos artículos no se correspondía en una real participación de las mujeres en los ámbitos sindicales.

\section{Conclusiones}

En el intento de aportar a la historia de las mujeres, a la historia que trabaja la diferencia sexual como una construcción cultural y a los estudios sobre los vínculos entre clase y género en Uruguay, se emprendió un recorrido observando un conjunto de artículos de prensa sindical de la industria de la carne entre 1946 y 1952, que tienen a las mujeres como centro de su preocupación. La intención del sindicato era "colocar" u "ocupar" a las mujeres obreras en determinados "lugares" o "puestos" sindicales, y a través de sus líneas discursivas también expresan los roles y representaciones de las mujeres en la clase trabajadora y en la sociedad.

Lo expresado allí se ajusta en gran medida a los cánones tradicionales que ubicaban y mantenían a las mujeres en el hogar atendiendo los deberes conyugales y maternos, representadas en imágenes de debilidad y delicadeza,

\footnotetext{
recibió en ocasión del fallecimiento de su esposo. (iLucha!, Montevideo, octubre de 1950, p.2, "Agradecimiento", por Delia Cóppola de Del Campo.)

61 iLucha!, Montevideo, enero de 1949, p.5, "Nota de agradecimiento", por Erika Heizmann.

62 LOBATO, Mirta, Historia de las trabajadoras... Ob. Cit. P.305.

63 iLucha!, Montevideo, marzo y noviembre de 1952.
} 
mientras que los varones eran los proveedores del hogar y sus cualidades se expresaban a través de la fuerza.

La capacidad biológica reproductiva de las mujeres las condenaba al destino de la "atención" del hogar. La maternidad era el factor determinante de la identidad femenina y el máximo horizonte de realización de las mujeres. Las particularidades del carácter o la personalidad de varones y mujeres eran asociadas a la "naturaleza" y no se las pensaba como resultado de factores políticos, históricos, culturales. Además de no atribuirles una trayectoria de vida propia, el trabajo para ellas no constituía un derecho, sino que era producto de la explotación despiadada del sistema. Las mujeres sufrían al abandonar sus hijas/os y en el trabajo podían ser objeto de abusos por parte de todos los varones que allí se encontraban.

La moral era una cuestión a la que el mundo de los y las trabajadoras prestaba una atención especial. Para las mujeres, la moral era una cuerda extremadamente floja de la cual podían caer en cualquier momento. En general la vida cotidiana de las mujeres se encontraba en duda en términos morales; el trabajo y el sindicato también las amenazaba.

La prensa sindical de la industria de la carne reflejó con insistencia su integración a la lucha. Las mujeres deberían añadir una actividad más a sus cotidianas vidas, una triple carga (trabajo doméstico, trabajo extradoméstico y participación sindical). Y también se agregaba un nuevo elemento para juzgar sus conductas: las que no participaban en las instancias sindicales eran señaladas como apáticas, desinteresadas de la lucha por los derechos de la familia obrera. Las mujeres en el sindicato debían ocupar un puesto, cooperando y colaborando unidas a los varones, complementando su lucha, con el fin de mejorar la vida familiar. Las divisiones sexuales en el trabajo se reproducían en el sindicato, los dos espacios estaban hegemonizados por los varones y sus prácticas masculinas.

Existía una intención de identificar algunos aspectos de las problemáticas que atañen a las mujeres, pero no se traducía en aspiraciones de emancipación. Ejemplo de ello ha sido la contradictoria actitud de promover la integración de 
las mujeres a la dinámica sindical, al tiempo que también se intentaba restituirlas cuanto antes al hogar a través de un proyecto de jubilación anticipada.

Por lo tanto, la lectura que realizaban los sindicatos pasaba por alto los factores determinantes y las diversas explotaciones de las cuales las mujeres eran víctimas. La clase no transformaría su estructura de pensamiento ni la trama de sus prácticas. Siendo que los sindicatos abogaban por un mundo diferente, por una transformación de la sociedad, el rol de los géneros no estaba en cuestión, al contrario, se reproducían y se profundizaban las nociones tradicionales de género. No había ideas alternativas o transgresoras de los patrones culturales predominantes.

\section{Bibliografía}

ACHA, Omar; HALPERIN, Paula (comp.) Cuerpos, géneros, identidades. Estudios de género en Argentina, Buenos Aires, Ediciones del Signo, 2000.

ARAÚJO, Ana María; BEHARES, Luis E.; SAPRIZA, Graciela Género y sexualidad en el Uruguay, Montevideo, Ed. Trilce, 2001.

BARRÁN, José Pedro, "Historia de la sensibilidad en el Uruguay. La cultura 'bárbara'. El disciplinamiento." Montevideo, EBO, 2017.

BARRANCOS, Dora.

-"Moral sexual, sexualidad y mujeres trabajadoras en el período de entreguerras", en DEVOTO, Fernando; MADERO, Mirta (dirs.), Historia de la vida privada en la Argentina. Tomo III. Buenos Aires, Ed. Taurus, 1999, pp.199-225.

-Mujeres en la sociedad argentina. Una historia de cinco siglos. Buenos Aires, Ed. Sudamericana, 2007.

CORES, Hugo, Las luchas de los Gremios Solidarios (1947-1952): neo-batllismo, protesta social y Fuerzas Armadas, Montevideo, EBO, Editorial Compañero, 1989.

D’ANTONIO, Débora y ACHA, Omar, “La clase obrera 'invisible’: imágenes y participación sindical de las obreras a mediados de la década de 1930 en Argentina" en ACHA, Omar; HALPERIN, Paula (comp.) Cuerpos, géneros, identidades. Estudios de género en Argentina, Buenos Aires, Ediciones del Signo, 2000. 
ERRANDONEA, Alfredo; COSTÁBILE, Daniel, Sindicato y sociedad en el Uruguay, Montevideo, FCU, 1969.

GONZÁLEZ SIERRA, Yamandú, Del hogar a la fábrica, ¿deshonra o virtud?, Montevideo, Ed. Nordan, 1994.

JUNG GARIBALDI, María Eugenia; RODRÍGUEZ DÍAZ, Universindo, "Importancia de la prensa sindical como fuente historiográfica" en Rodolfo PORRINI (comp.) Historia y memoria del mundo del trabajo, Montevideo, Imprenta Aragón, UdelaR, FHCE, CSIC, 2004, Pp. 143-160.

LLONA, Miren, "La prostitución y a identidad de la clase obrera en el tránsito del siglo XIX al XX. Un análisis de género a la obra literaria de Julián Zugazagoitia”, en Revista Historia Contemporánea 33, 2006. Pp. 719-740. Disponible https://www.ehu.eus/ojs/index.php/HC/article/view/4193/3739 (última consulta, junio 2019)

LOBATO, Mirta.

-Historia de las trabajadoras en la Argentina (1869-196o) Buenos Aires, Ed. Edhasa, 2007.

-La prensa obrera. Buenos Aires y Montevideo 189o-1958, Buenos Aires, Ed. Edhasa, 2009.

-"Dentro y fuera del lugar. Carne, trabajo e identidades de género en Argentina." En Historias cruzadas. Diálogos historiográficos sobre el mundo del trabajo en Argentina y Brasil, en SURIANO, Juan; SCHETTINI, Cristiana (comp.) Buenos Aires, Ed. Teseo, 2019. Disponible en https://www.teseopress.com/historiascruzadas/chapter/genero-ytrabajo/ (última consulta, mayo de 2019)

NAHUM, Benjamín; COCCHI, Ángel; FREGA, Ana; TROCHÓN, Yvette, Crisis política y recuperación económica 1930-1958, Historia uruguaya, Tomo 7, Montevideo, EBO, 1998.

PORRINI, Rodolfo.

-"Clase obrera, sindicatos y Estado en el Uruguay de la expansión industrial (1936-1947”, en Estudos Ibero-Americanos. PUCRS. v. XXIX. n. 2. 2003. $\quad$ P. 171-196. Disponible en http://www.fhuce.edu.uy/images/Ciencias_Historicas/Historia_Americ ana/Publicaciones\%20PAlvira/Clase obrera sindicatos y Estado en el Uruguay.pdf

-La nueva clase trabajadora uruguaya (1940-1950), Montevideo, FHCEUdelaR, 2005.

-"La sociedad movilizada" en Ana FREGA, et. al, Historia del Uruguay en el siglo XX (189o-2005), Montevideo, EBO, 2008. Pp.285-316.

RODRÍGUEZ VILLAMIL, Silvia; SAPRIZA, Graciela, Mujer, Estado y Política en el Uruguay del siglo XX, Montevideo, 1984.

SAGASTIZABAL, Marina, "Vivencias del tiempo social: compaginar la participación política, el cuidado y el empleo", en ARAÚJO, E.; DUQUE, E.; FRANCH, M.; DURAN, J. (eds.) Tempos Sociais $e$ o Mundo 
Contemporâneo - As crises, As Fases e as Ruturas Centro de Estudos de Comunicação e Sociedade, Universidade do Minho, 2014, Pp. 221-232.

SAGASTIZABAL, Marina; LEGARRETA, Matxalen, "La "triple presenciaausencia": una propuesta para el estudio del trabajo doméstico-familiar, el trabajo remunerado y la participación sociopolítica”, en Papeles del CEIC, vol. 2016/1, $\mathrm{n}^{0}$ 151, CEIC (Centro de Estudios sobre la Identidad Colectiva), Universidad del País Vasco, Pp. 1-29

SAPRIZA, Graciela, Los caminos de una ilusión. 1913: huelga de mujeres en Juan Lacaze, Montevideo, Ed. Fin de Siglo, 1993.

SCOTT, Joan, Género e Historia, México, Fondo de Cultura Económica, 2008. Disponible

en https://edisciplinas.usp.br/pluginfile.php/2185910/mod resource/conte nt/1/Scott\%2C\%20Joan\%20-\%20G\%C3\%A9nero\%20e\%20Historia.pdf (última consulta, marzo 2019)

TAKS, Javier, "La Clase Trabajadora y las obreras del Anglo" en Revista ENCUENTROS No6, Montevideo, octubre. CEIL-CEIU/FHCE y FCU. 1999, Pp. 211-230.

TROCHÓN, Yvette, “De grelas, cafishios y piringundines...” en Historias de la vida privada en el Uruguay, Tomo 3, Individuos y soledades (1920-1990) BARRÁN, José Pedro; CAETANO, Gerardo; PORZECANSKI, Teresa (dirs.) Montevideo, Ed. Taurus, 1998, Pp.62-102.

ZUBILLAGA, Carlos; BALBIS, Jorge, Prensa obrera y obrerista (1875-1905), Historia del movimiento sindical uruguayo, Tomo 2, Montevideo, EBO, 1986.

Cita sugerida: Martínez, Alesandra. (2019) "Roles y representaciones de la mujer obrera según la publicación sindical iLucha! de la industria de la carne (Uruguay), 1946-1952", Claves. Revista de Historia, Vol. 5, No 8, ISSN 2393-6584, pp.153-179. DOI:

http://dx.doi.org/10.25032/crh.v5i8.7 